16

\title{
Влияние термообработки на атомную структуру core-shell наночастиц PtCu в составе электрокатализаторов $\mathrm{PtCu} / \mathrm{C}$
}

\author{
(C) В.В. Прядченко ${ }^{1}$, С.В. Беленов ${ }^{1}$, Д.Б. Шемет ${ }^{1}$, В.А. Волочаев ${ }^{1}$, В.В. Срабионян ${ }^{1}$, \\ Л.А. Авакян ${ }^{1}$, Н.Ю. Табачкова ${ }^{2}$, В.Е. Гутерман ${ }^{1}$, Л.А. Бугаев ${ }^{1}$ \\ ${ }^{1}$ Южный фредеральный университет, \\ Ростов-на-Дону, Россия \\ ${ }^{2}$ Национальный исследовательский технологический университет „МИСиС“, \\ Москва, Россия \\ E-mail: vvpryadchenko@sfedu.ru
}

(Поступила в Редакцию 15 февраля 2017 г.)

Электрокатализаторы $\mathrm{PtCu} / \mathrm{C}$, содержащие биметаллические наночастицы $\mathrm{PtCu}$, синтезированы методом последовательного химического восстановления $\mathrm{Cu}^{2+}$ и $\mathrm{Pt}(\mathrm{IV})$ в углеродной суспензии, приготовленной на основе водного раствора этиленгликоля. Исследование атомной структуры приготовленных наночастиц $\mathrm{PtCu}$, а также полученных после термической обработки при $350^{\circ} \mathrm{C}$ было выполнено с помощью $\mathrm{Pt} L_{3}$ и $\mathrm{Cu} K$-спектров рентгеновского поглощения в протяженной области (EXAFS), методов просвечивающей электронной микроскопии (TEM) и порошковой рентгеновской дифракции (XRD). Согласованный анализ TEM-микрофотографий, XRD-профилей, а также EXAFS-спектров позволил установить, что в состав полученных электрокатализаторов входят наночастицы $\mathrm{PtCu}$ со структурой $\mathrm{Cu}$-ядро-Pt-оболочка, а также оксиды меди $\mathrm{Cu}_{2} \mathrm{O}$ и $\mathrm{CuO}$. Термическая обработка электрокатализаторов при $350^{\circ} \mathrm{C}$ приводит к сплавлению биметаллических наночастиц с формированием как однородных, так и упорядоченных твердых растворов $\mathrm{PtCu}$, а также к частичному восстановлению медных оксидов.

Исследования структурных характеристик наночастиц $\mathrm{PtCu}$ проведены при финансовой поддержке Южного федерального университета (грант № ВнГр-07.2017-06). Методика синтеза катализатора $\mathrm{PtCu} / \mathrm{C}$ разработана в рамках выполнения гранта РФФИ № 14-29-04041 офи_м.

DOI: $10.21883 /$ FTT.2017.08.44771.43

\section{1. Введение}

Одним из ключевых факторов, определяющих эффективность работы топливных элементов с протонообменной мембраной (РЕМFС), является скорость реакции восстановления кислорода (РВК) в условиях эксплуатации. Наночастицы платины, нанесенные на углеродный носитель, являются одним из основных компонентов каталитических слоев, используемых в низкотемпературных топливных элементах для ускорения РВК. Коммерческое применение этих материалов сдерживается следующими факторами: 1) недостаточной коррозионноморфологической стабильностью в процессе эксплуатации как наночастиц, так и самого металл-углеродного композита в целом; 2) относительно высокой стоимостью. Эффективным способом преодоления этих проблем и получения перспективных электрокатализаторов РВК может быть синтез биметаллических наночастиц состава $\mathrm{Pt} M$ (где $M$ - переходный металл, такой как $\mathrm{Cu}$, $\mathrm{Co}, \mathrm{Ni}, \mathrm{Ag}$ и т.д.) со структурой ядро-оболочка (где оболочка образована атомами $\mathrm{Pt}$, а ядро - атомами $M$ ), осажденных на высокоразвитой поверхности углеродных носителей [1-4].

Идентификация архитектуры биметаллических наночастиц - необходимый компонент исследований, связанных с оптимизацией структуры и улучшением функциональных характеристик электрокатализаторов $\mathrm{PtM} / \mathrm{C}$.
При этом необходимо учитывать, что формирование множества биметаллических наночастиц происходит в условиях самоорганизации вещества, следствием чего может являться большее или меньшее отклонение состава и архитектуры отдельных наночастиц от неких усредненных (заданных) значений $[2,5]$.

Архитектура биметаллических наночастиц в $\mathrm{Pt} M / \mathrm{C}$ материалах может изменяться в результате их термообработки [6-9]. В зависимости от состава и структуры исходных наночастиц, температуры и длительности нагрева образца возможны как сегрегация компонентов, так и их более однородное распределение по объему частицы. Ранее было обнаружено [10], что температурная обработка электрокатализаторов $\mathrm{PtCu} / \mathrm{C}$ при $300^{\circ} \mathrm{C}$ приводит к структурным изменениям, проявляемым в сдвиге дифракционных максимумов на порошковых рентгеновских дифрактограммах. С целью выяснения характера таких изменений с изменениями в архитектуре биметаллических наночастиц $\mathrm{PtCu}$ в результате термической обработки в настоящей работе выполнены структурные исследования электрокатализаторов $\mathrm{PtCu} / \mathrm{C}$, полученных в результате температурной обработки при $T=350^{\circ} \mathrm{C}$. Структурные исследования выполнены с использованием 1) $\mathrm{Pt} L_{3}$ - и $\mathrm{Cu} K$-спектров рентгеновского поглощения в протяженной энергетической области за краем поглощения (extended $X$-ray absorption fine structure - EXAFS) [11-14]; 2) просвечивающей 
электронной микроскопии (transmission electron microscopy - TEM); 3) порошковой рентгеновской дифракции ( $X$-ray diffraction - XRD). Еще одной целью работы является установление чувствительности метода EXAFS-спектроскопии к изменениям архитектуры множества биметаллических наночастиц в результате проведенного термического воздействия. Описание методики синтеза и последующей температурной обработки представлено в подразделе 2.1, экспериментальных методик измерений - в подразделе 2.2. Результаты согласованного анализа данных, полученных методами TEM, XRD и EXAFS обсуждаются в разделе 3.

\section{2. Экспериментальные методы}

2.1. Синтез наночастиц. Наночастицы $\mathrm{PtCu}$, нанесенные на микрочастицы углерода, были синтезированы путем химического восстановления $\mathrm{Pt}(\mathrm{IV})$ $\left(\mathrm{H}_{2} \mathrm{PtCl}_{6} \cdot 6 \mathrm{H}_{2} \mathrm{O}\right)$ и $\mathrm{Cu}^{2+}\left(\mathrm{CuSO}_{4} \cdot 5 \mathrm{H}_{2} \mathrm{O}\right)$ в суспензии углеродного порошка (Vulcan XC72, Cabot), приготовленной на основе водно-этиленгликолевого раствора при $\mathrm{pH}=10$ (избыток $\mathrm{NH}_{3}$ ). Объемное отношение вода:этиленгликоль составляло 1:1. В качестве восстанавливающего агента был использован $0.5 \mathrm{M}$ раствор $\mathrm{NaBH}_{4}$. Чтобы получить наночастицы со структурой ядро-оболочка с ядром, состоящим из атомов $\mathrm{Cu}$, и внешней оболочкой из атомов $\mathrm{Pt}$, был использован метод последовательного химического восстановления. На первом этапе путем восстановления меди в углеродной суспензии с небольшой добавкой платины, приготовленной на основе раствора $\mathrm{CuSO}_{4}$ и $\mathrm{H}_{2} \mathrm{PtCl}_{6}$, был получен наноструктурный материал $\mathrm{Cu}_{9} \mathrm{Pt} / \mathrm{C}$. Ранее нами было показано [5], что введение $10 \% \mathrm{Pt}$ на стадии синтеза ядер меди позволяет получать наночастицы с меньшим средним размером кристаллитов и отсутствием фаз оксидов меди. Затем готовилась суспензия полученного композита $\mathrm{Cu}_{9} \mathrm{Pt} / \mathrm{C}$ в растворе вода-этиленгликоль с тем же соотношением компонентов, значение $\mathrm{pH}$ доводилось до 10 водным раствором $\mathrm{NH}_{3}$. В полученную суспензию добавлялись рассчитанное количество водного раствора $\mathrm{H}_{2} \mathrm{PtCl}_{6}$ и $0.5 \mathrm{M}$ раствор $\mathrm{NaBH}_{4}$. Отметим, что для уменьшения вклада процесса гальванического замещения атомов меди на поверхности наночастиц атомами платины введение свежеприготовленного раствора $\mathrm{NaBH}_{4}$ происходило практически сразу (2-3 s) после добавления прекурсора платины к суспензии $\mathrm{Cu}_{9} \mathrm{Pt} / \mathrm{C}$. Конечный материал $\mathrm{PtCu} / \mathrm{C}$ фильтровался, промывался ацетоном и водой, после чего высушивался в эксикаторе над $\mathrm{P}_{2} \mathrm{O}_{5}$.

Часть полученного катализатора обрабатывалась в атмосфере аргона при температуре $350^{\circ} \mathrm{C}$ с использованием печи ПТК-1,2-40 (НПП „Теплоприбор“) по следующей схеме: быстрый (около $10 \mathrm{~min}$ ) нагрев до заданной температуры, выдержка при заданной температуре в течение $1 \mathrm{~h}$, медленное самопроизвольное охлаждение до комнатной температуры после отключения нагревания в течение $4-5 \mathrm{~h}$.

Состав полученных нанокатализаторов $\mathrm{PtCu} / \mathrm{C}$ coответствует массовой доле металлической составляющей $\sim 30 \%$. Для определения соотношения металлов $\mathrm{Pt}: \mathrm{Cu}$ использовался метод рентгенофлуоресцентного анализа на спектрометре с полным внешним отражением рентгеновского излучения РФС-001. Спектрометр РФС-001 разработан в отделе аналитического приборостроения НИИ физики ЮФУ, диапазон определяемых химических элементов по Периодической таблице Менделеева - от Al до U. В состав спектрометра входят рентеновская трубка (материал анода Мо, мощность $7.5 \mathrm{~W}$, напряжение $50 \mathrm{kV}$ ), рентгеновское зеркало из аморфного кварца $\mathrm{SiO}_{2}$, система коллимирующих щелей, полупроводниковый энергодисперсионный детектор Amptek c энергетическим разрешением $\sim 180 \mathrm{eV}$. Время экспозиции спектров рентгеновской флуоресценции $300 \mathrm{~s}$. Регистрация и обработка рентгеновских флуоресцентных спектров проводились с использованием разработанного совместно со спектрометром программного обеспечения UniveRS (Свидетельство государственной регистрации программы для ЭВМ № 2010615318 от 18.08.2010 г., правообладатель ЮФУ). Атомное соотношение металлов в исследуемых материалах составляет $\mathrm{Pt}_{0.8} \mathrm{Cu}$ как до, так и после термообработки.

2.2. XRD, TEM и EXAFS-и з ме р ен и я. Порошковые рентгенограммы материалов регистрировались на автоматическом дифрактометре ARL X'TRA с использованием $\mathrm{Cu} K$-излучения $(\langle\lambda\rangle=0.15418 \mathrm{~nm})$. Измерения проводились в непрерывном режиме с шагом $0.02^{\circ}$ и скоростью регистрации $2-4 \%$ min в интервале углов $2 \theta=15-55^{\circ}$. Для прецизионных измерений применялся пошаговый режим $\left(0.08^{\circ}\right.$ с задержкой $\left.12 \mathrm{~s}\right)$ в интервале $15-90^{\circ}$. Средний размер кристаллитов рассчитывался по формуле Шеррера, как это описано в [15].

Микрофотографии синтезированных материалов получены на микроскопе JEM-2100 (JEOL, Япония) при ускоряющем потенциале $200 \mathrm{kV}$ и разрешении $0.2 \mathrm{~nm}$. Для проведения электронно-микроскопических исследований каплю специально приготовленной суспензии (около $0.5 \mathrm{mg}$ катализатора диспергировали ультразвуком в $1 \mathrm{ml}$ изопропанола в течение $5 \mathrm{~min}$ ) наносили на медную сетку, покрытую тонким слоем углеродной пленки (для фиксации микрочастиц на поверхности) и сушили около $20 \mathrm{~min}$ в воздушной атмосфере при комнатной температуре.

$\mathrm{Pt} L_{3}$ - и $\mathrm{Cu} K$-спектры EXAFS исследуемых материалов были измерены на станции $\mu$ Spot источника синхротронного излучения BESSY-II (Берлин, Германия). Среднее значение тока электронного пучка в накопительном кольце в ходе эксперимента составляло $300 \mathrm{~mA}$ в режиме Top-Up. Измерения проводились в режиме на прохождение с использованием кремниевого ( $\mathrm{Si}$ (111)) монохроматора, двух ионизационных камер для измерения интенсивностей падающего и прошедшего пучков, 
a также ріn-диода для измерения интенсивности пучка за реперным образцом (платиновая и медная фольги). Шаг по энергии в околопороговой области составлял $\Delta E=1.0 \mathrm{eV}$ и изменялся квадратично в дальней области для обеспечения постоянного шага в шкале волновых чисел $\Delta k=0.05 \AA^{-1}$.

\section{3. Результаты}

Порошковые дифрактограммы материала $\mathrm{PtCu} / \mathrm{C}$ до и после термической обработки, представленные на рис. 1, типичны для платиносодержащих катализаторов на углеродном носителе и содержат отражения, соответствующие гранецентрированной кубической решетке с пространственной группой $F m \overline{3} m$. Для материала до обработки максимумы отражений на дифрактограммах смещены относительно максимумов для чистой платины в область больших углов $2 \theta$ (рис. 1), что может быть связано либо с образованием твердого раствора замещения меди в платине, либо с наложением отражений платины и меди в случае формирования наночастиц со структурой $\mathrm{Cu}$-ядро-Pt-оболочка. На всех представленных порошковых рентгенограммах отсутствуют отражения, соответствующие фазам чистой меди или ее оксидов (за исключением очень слабого отражения при $2 \theta \sim 35^{\circ}$, характерного для направления 111 в $\mathrm{Cu}_{2} \mathrm{O}$ ), что не исключает наличия в составе полученных материалов некоторого количества этих веществ в рентгеноаморфном состоянии.

Анализ порошковых дифрактограмм полученных материалов показал, что термическая обработка в инертной атмосфере приводит к уменьшению полной ширины пика на половине высоты (full width at half maximum FWHM) и соответственно к укрупнению среднего размера кристаллитов от 2.3 до $11.5 \mathrm{~nm}$. Кроме того, термическая обработка приводит к сдвигу максимумов отражения в область больших углов $2 \theta$, что свидетельствует

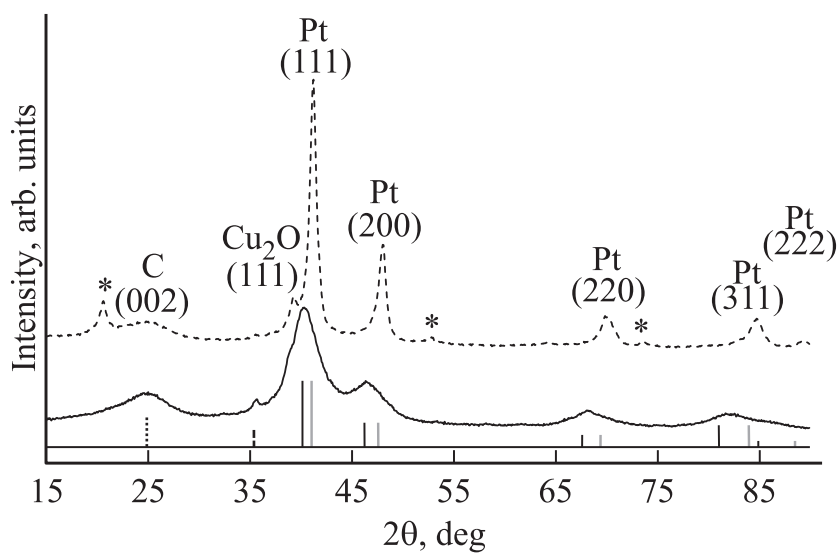

Рис. 1. Рентгеновские дифрактограммы приготовленного (сплошная кривая) и термически обработанного (штриховая кривая) электрокатализаторов $\mathrm{PtCu} / \mathrm{C}$. Звездочками отмечены сверхструктурные отражения. об уменьшении параметра кристаллической решетки металлической фазы и может быть связано как с вхождением в состав твердого раствора рентгеноаморфной меди, так и с превращением наночастиц с архитектурой оболочка-ядро в частицы твердого раствора за счет взаимодиффузии атомов платины и меди. Для выяснения причин изменения параметра кристаллической решетки в процессе термической обработки необходимо привлечь дополнительные методы исследования структуры наночастиц. Отметим, что после термической обработки при $350^{\circ} \mathrm{C}$ на рентгенограмме появляются дополнительные отражения при значениях $2 \theta \sim 20.7,53.2,73.4^{\circ}$, которые не связаны с оксидами или гидроксидами меди. Одним из возможных объяснений появления этих максимумов является формирование сверхструктуры, т.е. образование наночастиц со структурой интерметаллида состава $\mathrm{PtCu}$ в процессе нагрева и последующего медленного охлаждения [7,16]. Отметим, что формирование упорядоченной структуры интерметаллида, по мнению ряда авторов, может приводить к повышению каталитической активности [7].

ТЕМ-микрофотографии приготовленных и полученных после термической обработки электрокатализаторов представлены на рис. 2. В катализаторах до термической обработки присутствуют наночастицы разного размера и строения. На центральном изображении рис. 2, $a$ (масштаб $20 \mathrm{~nm}$ ) можно выделить небольшие однородные наночастицы (темные и светлые маленькие пятна), а также более крупные неоднородные наночастицы, которые могут быть отнесены к наночастицам со структурой ядро-оболочка (крупные пятна со светлой внутренней областью и более темной поверхностью). Пример такой наночастицы более крупно представлен справа на рис. 2,a. В катализаторах, подвергнутых термической обработке, все наночастицы, вероятно, имеют одинаковую структуру, причем на ТЕМ-снимках таких катализаторов отсутствуют признаки структуры ядро-оболочка (однородные серые пятна, рис. 2, $b$ ). Исходя из качественного анализа ТЕМ-микрофотографий можно предположить, что термическая обработка приводит к сплавлению изначально неоднородных биметаллических наночастиц $\mathrm{PtCu}$.

Гистограммы распределений частиц по размерам, полученные из ТЕМ-микрофотографий, представлены на рис. 3. Для набора достаточной статистики были измерены размеры порядка 1000 наночастиц для каждого образца. На основании полученных данных можно сделать вывод об увеличении средних размеров наночастиц в результате термообработки (сдвиг максимума распределения в сторону больших значений $D$ ). Наблюдаемый бимодальный характер распределения наночастиц по размерам можно объяснить наличием в исходном катализаторе наночастиц с разной архитектурой (рис. 2,a), которые характеризуются различными размерными распределениями. Поэтому даже после перераспределения атомов меди и платины в биметаллических наночастицах 

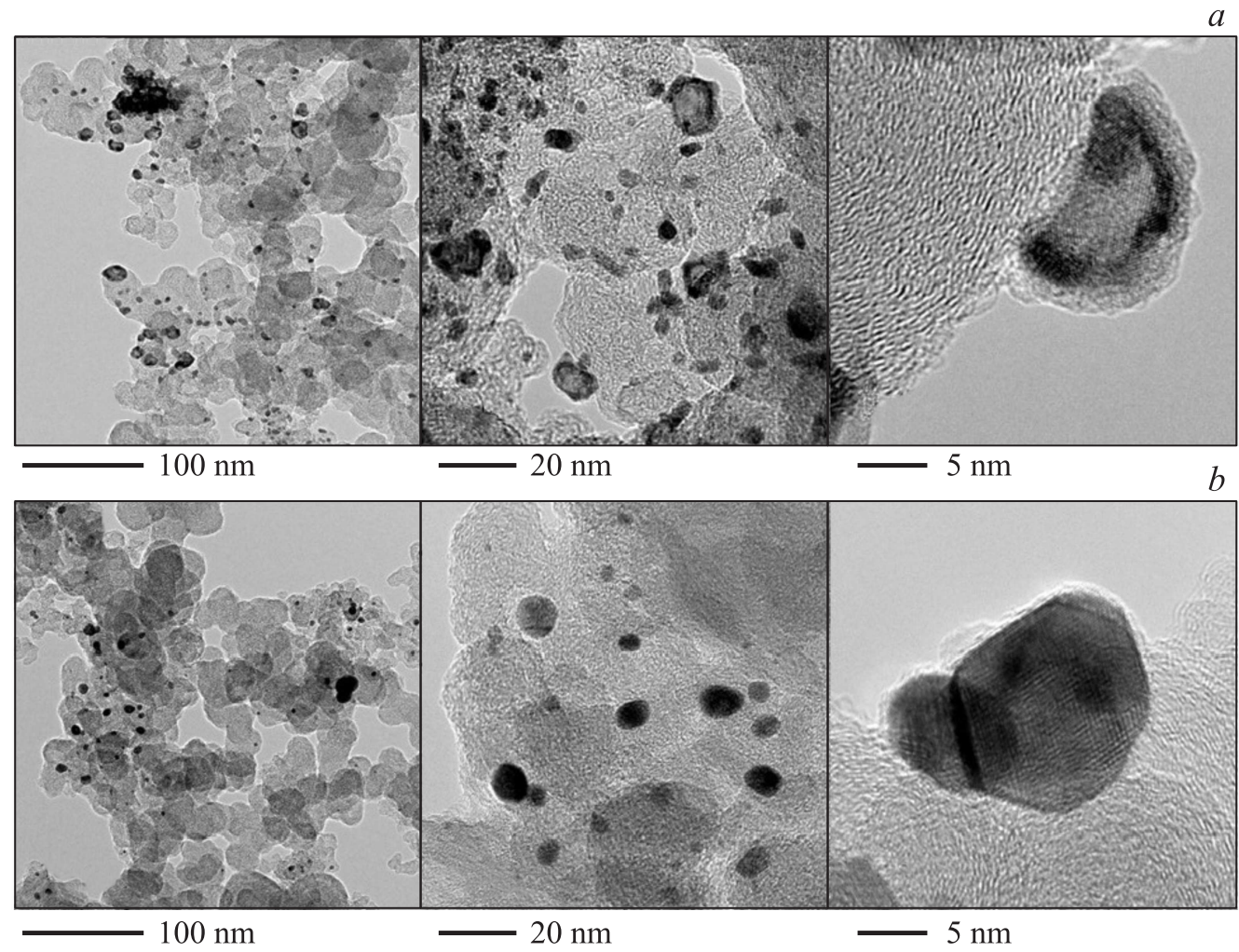

Рис. 2. ТЕМ-микрофотографии приготовленного $(a)$ и термически обработанного $(b)$ электрокатализаторов $\mathrm{PtCu} / \mathrm{C}$.

в результате термической обработки неоднородность размерного распределения сохраняется.

Параметры структуры ближнего окружения атомов платины и меди в биметаллических наночастицах $\mathrm{PtCu}$ в синтезированных материалах были получены с помощью метода EXAFS-спектроскопии [17]. Первичная обработка $\mathrm{Pt} L_{3}$ - и $\mathrm{Cu} K$-спектров EXAFS, включающая нормировку коэффициента поглощения $\mu(E)$ и последующее выделе-

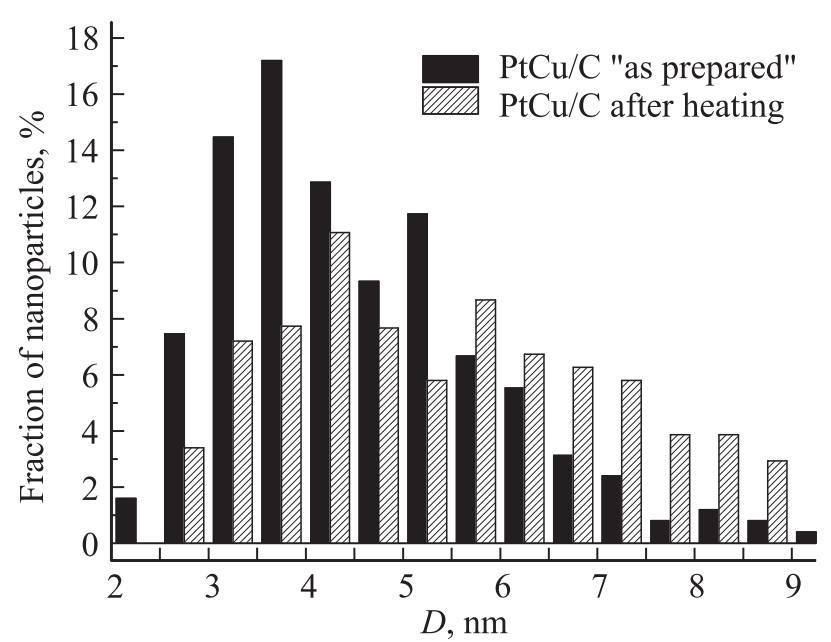

Рис. 3. Гистограммы распределения наночастиц по размерам в составе катализатора $\mathrm{PtCu} / \mathrm{C}$ до (темные столбики) и после (заштрихованные столбики) температурной обработки. ние из него осциллирующей части $\chi(k)$, осуществлялась с помощью широко распространенного программного пакета Ifeffit $[18,19]$. На рис. 4 сопоставлены модули Фурье-образов $|F(R)|$ экспериментальных и теоретических $\mathrm{Cu} K$ - и $\mathrm{Pt} L_{3}$-спектров EXAFS. Фитинг Фурьеобразов $F(R)$ EXAFS-спектров был выполнен с использованием следующих выражений для осциллирующих частей $\chi(k)$ коэффициентов рентгеновского поглощения платины и меди:

$$
\begin{gathered}
\chi_{\mathrm{Pt}}(k)=S_{0}^{2}\left(N_{\mathrm{Pt}-\mathrm{Pt}} \chi_{\mathrm{Pt}-\mathrm{Pt}}+N_{\mathrm{Pt}-\mathrm{Cu}} \chi_{\mathrm{Pt}-\mathrm{Cu}}\right), \\
\chi_{\mathrm{Cu}}(k)=S_{0}^{2}\left(N_{\mathrm{Cu}-\mathrm{Cu}} \chi_{\mathrm{Cu}-\mathrm{Cu}}+N_{\mathrm{Cu}-\mathrm{Pt}} \chi_{\mathrm{Cu}-\mathrm{Pt}}+N_{\mathrm{Cu}-\mathrm{O}} \chi_{\mathrm{Cu}-\mathrm{O}}\right),
\end{gathered}
$$

где $\chi_{\mathrm{Pt}-\mathrm{Pt}}, \chi_{\mathrm{Pt}-\mathrm{Cu}}, \chi_{\mathrm{Cu}-\mathrm{Pt}}, \chi_{\mathrm{Cu}-\mathrm{Cu}}-$ вклады в $\chi(k)$, которые соответствуют процессам рассеяния фотоэлектронной волны на одном ближайшем атоме определенного типа (первый нижний индекс - поглощающий атом, второй - рассеивающий) и определяются рядом структурных и неструктурных параметров. Для определения структуры ближнего окружения атомов $\mathrm{Pt}$ и $\mathrm{Cu}$ в наночастицах $\mathrm{PtCu}$ в условиях сильной корреляции между параметрами применялась методика обработки Фурье-образов экспериментальных EXAFS-спектров Pt и $\mathrm{Cu}[2,20]$, основанная на определении структурных параметров с помощью наборов их значений, полученных для разных длин $\Delta k$-интервалов и разных весовых множителей $k^{n}(n=1,2,3)$, используемых при Фурьепреобразовании функции $\chi(k)$. В настоящей работе та- 

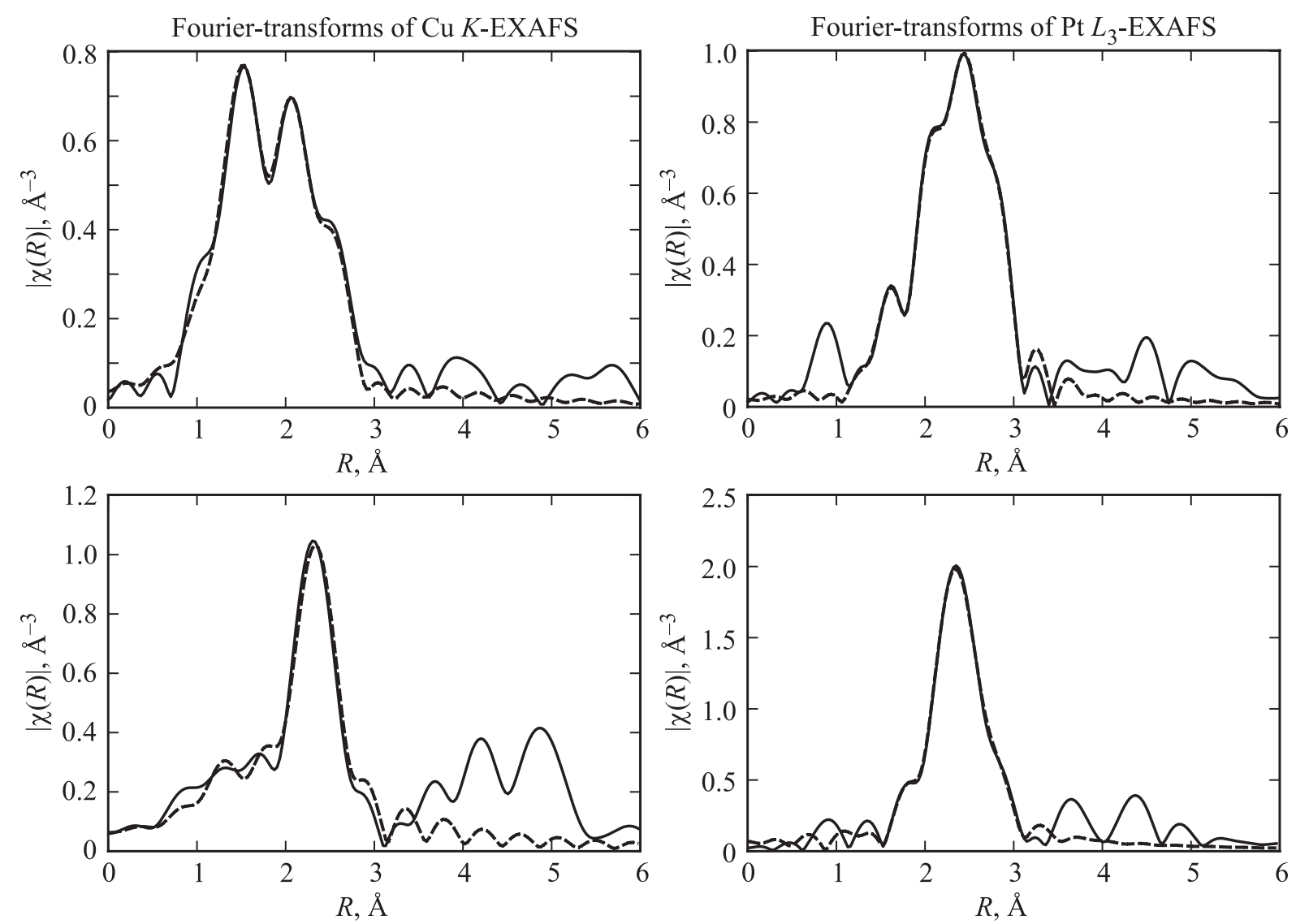

Рис. 4. Экспериментальные (сплошные кривые) и теоретические (штриховые кривые) модули Фурье-образов Сu $K$ - (слева) и $\mathrm{Pt} L_{3^{-}}$(справа) спектров EXAFS исходных (вверху) и обработанных при $350^{\circ} \mathrm{C}$ (внизу) электрокатализаторов $\mathrm{PtCu} / \mathrm{C}$.

кой подход был дополнен процедурой одновременного фитинга EXAFS-спектров $\mathrm{Pt}$ и $\mathrm{Cu}$ для каждого из изучаемых материалов, в рамках которого некоторые из подгоночных параметров связывались между собой определенными соотношениями. Такой подход позволил уменьшить общее число варьируемых параметров при фитинге спектров платины и меди и тем самым повысить устойчивость результатов.

В результате фитинга Фурье-образов экспериментальных $\mathrm{Pt} L_{3^{-}}$и $\mathrm{Cu} K$-спектров EXAFS были получены значения как структурных, так и неструктурных параметров: парциальных координационных чисел $N_{\mathrm{Pt}-\mathrm{Pt}}$, $N_{\mathrm{Pt}-\mathrm{Cu}}, N_{\mathrm{Cu}-\mathrm{Pt}}, N_{\mathrm{Cu}-\mathrm{Cu}}$ и соответствующих параметров Дебая-Валлера $\sigma_{\mathrm{Pt}-\mathrm{Pt}}^{2}, \quad \sigma_{\mathrm{Pt}-\mathrm{Cu}}^{2}=\sigma_{\mathrm{Cu}-\mathrm{Pt}}^{2}, \sigma_{\mathrm{Cu}-\mathrm{Cu}}^{2}$, межатомных расстояний $R_{\mathrm{Pt}-\mathrm{Pt}}, R_{\mathrm{Cu}-\mathrm{Pt}}=R_{\mathrm{Pt}-\mathrm{Cu}}, R_{\mathrm{Cu}-\mathrm{Cu}}$ и энергетических сдвигов $E_{0}(\mathrm{Pt})$ и $E_{0}(\mathrm{Cu})[11]$.

Полученные значения параметров ближнего окружения атомов $\mathrm{Pt}$ и $\mathrm{Cu}$ в биметаллических наночастицах $\mathrm{PtCu}$ приведены в табл. 1 и 2. Значения структурных параметров для приготовленных катализаторов согласуются со значениями, определенными ранее для аналогичных материалов [3,4]. Сразу следует обратить внимание на относительно малые значения парциальных координационных чисел $N_{\mathrm{Cu}-\mathrm{Cu}}$ и $N_{\mathrm{Cu}-\mathrm{Pt}}$, сопоставимые по величине со значением $N_{\mathrm{Cu}-\mathrm{O}}$. Их малость свидетель- ствует о том, что в катализаторах как до, так и после термообработки имеется значительное количество оксида меди (где среди ближайших соседей меди отсутствуют атомы металлов), который, как это было отмечено выше, довольно слабо проявляется на дифрактограммах (рис. 3). Последнее может быть обусловлено как малыми размерами частиц оксида, так и их аморфностью. Кроме того, несмотря на то что на дифрактограммах присутствует максимум, соответствующий оксиду одновалентной меди $\mathrm{Cu}_{2} \mathrm{O}$, представленные в табл. 2 средние значения межатомных расстояний $R_{\mathrm{Cu}-\mathrm{O}}$ характерны для оксида двухвалентной меди $\mathrm{CuO}$ [21]. Это в свою очередь означает, что в материалах до обработки преоб-

Таблица 1. Средние значения парциальных координационных чисел для атомов $\mathrm{Pt}$ и $\mathrm{Cu}$ в биметаллических наночастицах $\mathrm{PtCu}$, входящих в состав исследуемых электрокатализаторов

\begin{tabular}{l|c|c|c|c|c}
\hline \multirow{2}{*}{ Образец $\mathrm{PtCu} / \mathrm{C}$} & \multicolumn{5}{|c}{ Парциальные координационные числа } \\
\cline { 2 - 6 } & $N_{\mathrm{Pt}-\mathrm{Pt}}$ & $N_{\mathrm{Pt}-\mathrm{Cu}}$ & $N_{\mathrm{Cu}-\mathrm{Pt}}$ & $N_{\mathrm{Cu}-\mathrm{Cu}}$ & $N_{\mathrm{Cu}-\mathrm{O}}$ \\
\hline Исходный & 5.5 & 2.1 & 1.6 & 2.0 & 2.2 \\
После & 5.9 & 5.8 & 3.6 & 2.5 & 2.0 \\
термообработки & & & & &
\end{tabular}


Таблица 2. Средние значения параметров структуры ближнего окружения атомов $\mathrm{Pt}$ и $\mathrm{Cu}$ в биметаллических наночастицах $\mathrm{PtCu}$, входящих в состав исследуемых электрокатализаторов

\begin{tabular}{l|c|c|c|c|c|c|c|c}
\hline \multirow{2}{*}{ Образец PtCu/C } & \multicolumn{3}{|c|}{ Межатомные расстояния, $\AA$} & \multicolumn{4}{c}{ Параметры Дебая-Валлера, $\AA^{2}$} \\
\cline { 2 - 9 } & $R_{\mathrm{Pt}-\mathrm{Pt}}$ & $R_{\mathrm{Pt}-\mathrm{Cu}}$ & $R_{\mathrm{Cu}-\mathrm{Cu}}$ & $R_{\mathrm{Cu}-\mathrm{O}}$ & $\sigma_{\mathrm{Pt}-\mathrm{Pt}}^{2}$ & $\sigma_{\mathrm{Pt}-\mathrm{Cu}}^{2}$ & $\sigma_{\mathrm{Cu}-\mathrm{Cu}}^{2}$ & $\sigma_{\mathrm{Cu}-\mathrm{O}}^{2}$ \\
\hline Исходный & 2.74 & 2.64 & 2.54 & 1.95 & 0.005 & 0.006 & 0.008 & 0.005 \\
После термообработки & 2.69 & 2.66 & 2.63 & 1.97 & 0.004 & 0.007 & 0.007 & 0.011
\end{tabular}

ладает наличие оксида меди (II), в котором каждый атом меди координирован четырьмя атомами кислорода. Это позволяет весьма приближенно оценить долю атомов меди в составе оксида от их общего числа в катализаторе $\mathrm{PtCu} / \mathrm{C}$, используя следующее соотношение [22,23]:

$$
C=\left\langle N_{\mathrm{Cu}-\mathrm{O}}\right\rangle / N_{\mathrm{Cu}-\mathrm{O}}
$$

где $C$ - доля атомов меди, входящих в состав оксида, $\left\langle N_{\mathrm{Cu}-\mathrm{O}}\right\rangle-$ усредненное по образцу число ближайших атомов кислорода, получаемое из анализа EXAFS, $N_{\mathrm{Cu}-\mathrm{O}}-$ координационное число меди в оксиде. Оценка доли атомов меди в составе оксида дает $C \sim 0.55$ и $\sim 0.50$ до и после термообработки соответственно. Наблюдаемое увеличение суммарного координационного числа медь-металл вместе с уменьшением координационного числа медь-кислород может быть связано с частичным восстановлением ионов меди в процессе термической обработки [24]. Сделанный вывод подтверждается результатами анализа химического состава наночастиц, выполненного для аналогичных материалов до и после их обработки в кислоте [3], в результате которой около половины атомов меди вымывается из образца. Отметим, что анализ химического состава исследуемых материалов, выполненный до и после длительного электрохимического тестирования, также подтверждает факт вымывания приблизительно 50\% меди из образцов.

Сумма парциальных координационных чисел платины в приготовленном катализаторе $(\sim 7.6)$ заметно меньше, чем в катализаторе после термообработки $(\sim 11.7)$. Малое среднее число ближайших соседей платины в катализаторе до обработки характерно для наночастиц оболочка-ядро, в которых атомы платины находятся преимущественно в поверхностном слое - оболочке. Увеличение же значения координационного числа платины до величины $\sim 11.7$ объясняется существенным уменьшением доли атомов $\mathrm{Pt}$, находящихся на поверхности наночастицы, и подтверждает сделанное ранее предположение о сплавлении наночастиц до твердого раствора.

Важным источником информации о строении наночастиц помимо парциальных координационных чисел являются средние межатомные расстояния $R_{\mathrm{Pt}-\mathrm{Pt}}, R_{\mathrm{Pt}-\mathrm{Cu}}$ и $R_{\mathrm{Cu}-\mathrm{Cu}}$. Для понимания связи наблюдаемых средних значений межатомных расстояний между атомами платины и меди со структурой наночастиц может оказаться эффективным рассмотрение парных радиальных функций распределения атомов (ПРФРА) в наночастице, получаемых в результате молекулярно-динамических (МД) расчетов [2].

Отметим, что прямое сопоставление рассчитанных межатомных расстояний с расстояниями, полученными из данных EXAFS, оказывается неэффективным по нескольким причинам. Во-первых, рассчитываемые расстояния оказываются зависящими от размера, строения и даже формы наночастиц, что может приводить к расхождениям порядка $0.02 \AA$; во-вторых, МДпотенциал является приближенным и узкоспециализированным. В частности, используемый потенциал ЕМТ (см. далее) хорошо описывает металлы и бинарные сплавы некоторых $d$-элементов ( $\mathrm{Pt}, \mathrm{Cu}, \mathrm{Ag})$, но оказывается непригодным для описания взаимодействия ионов меди с кислородом или подложкой, роль которого может быть существенной. Однако тенденции изменения расстояний, связанные с силовыми характеристиками потенциалов и изменениями архитектуры металлических наночастиц, воспроизводятся адекватно, что позволяет сравнивать экспериментально наблюдаемые изменения с рассчитанными теоретически.

В настоящей работе для МД-расчетов использовался потенциал взаимодействия ЕМТ [25], который представляет собой реализацию модели погруженного атома с параметрами модели, рассчитанными из первых принципов. Построение ПРФРА выполнялось в несколько этапов: 1) оптимизация положения атомов исходного кластера методом Бройдена-Флетчера-ГольдфарбаШанно [26-28]; 2) приведение в равновесие с ланжевеновским термостатом $(300 \mathrm{~K})$ в течение 10 ps с шагом в 1 fs [29]; 3) наконец, сбор статистики о движении атомов с тем же термостатом в течение еще 10 ps.

Исходные модельные кластеры различаются распределением атомов меди и платины при фиксированных форме, размере $(4 \mathrm{~nm})$ и соотношении компонентов для того, чтобы можно было делать выводы о связи межатомных расстояний с архитектурой наночастиц. Рассмотрены следующие типы архитектур: 1) неупорядоченный (гомогенный) твердый раствор, в котором атомы разных типов распределены с помощью генератора случайных чисел; 2) слоистая структура, моделирующая интерметаллид [7]; 3) структура ядро-оболочка. Для построения моделей, выполнения моделирования и расчета ПРФРА были написаны Python-программы с использованием 
Таблица 3. Средние межатомные расстояния первой координационной сферы в модельных атомных кластерах $\mathrm{PtCu}$ различной архитектуры, полученных в результате МД расчетов

\begin{tabular}{|c|c|c|c|c|}
\hline \multicolumn{2}{|c|}{$\begin{array}{c}\text { Тип архитектуры } \\
\text { наночастицы }\end{array}$} & $\begin{array}{c}\left\langle R_{\mathrm{Pt}-\mathrm{Pt}}\right\rangle, \\
\AA\end{array}$ & $\begin{array}{c}\left\langle R_{\mathrm{Pt}-\mathrm{Cu}}\right\rangle, \\
\AA\end{array}$ & $\begin{array}{c}\left\langle R_{\mathrm{Cu}-\mathrm{Cu}}\right\rangle, \\
\AA\end{array}$ \\
\hline Ядро-оболочка & & 2.74 & 2.67 & 2.57 \\
\hline $\begin{array}{l}\text { Однородный } \\
\text { твердый раствор }\end{array}$ & & 2.71 & 2.65 & 2.63 \\
\hline $\begin{array}{l}\text { Упорядоченный } \\
\text { твердый раствор }\end{array}$ & & 2.71 & 2.64 & 2.67 \\
\hline
\end{tabular}

библиотеки ASE [30]. Полученные в результате оптимизации данных структур средние межатомные расстояния до ближайших соседей (первая координационная сфера) приведены в табл. 3.

В случае частиц ядро-оболочка рассчитанные межатомные расстояния $\left\langle R_{\mathrm{Pt}-\mathrm{Pt}}\right\rangle=2.74 \AA \quad$ и $\left\langle R_{\mathrm{Cu}-\mathrm{Cu}}\right\rangle=$ $=2.57 \AA$ (табл. 3) близки к значениям межатомных расстояний, соответствующим металлическим образцам $\left(R_{\mathrm{Pt}-\mathrm{Pt}}=2.77 \AA, R_{\mathrm{Cu}-\mathrm{Cu}}=2.55 \AA[31]\right)$, причем изменения более существенны для атомов вблизи поверхности наночастицы (т. е. атомов платины). Такие же тенденции наблюдаются и для межатомных расстояний приготовленных катализаторов, полученных из анализа EXAFS (табл. 2): расстояние $R_{\mathrm{Pt}-\mathrm{Pt}}=2.74 \AA$ на $0.03 \AA$ меньше, чем в металлической платиновой фольге, а отличие расстояния $R_{\mathrm{Cu}-\mathrm{Cu}}=2.54 \AA$ от расстояния в металлической медной фольге находится на уровне погрешности $(\Delta R \sim 0.01 \AA)$.

После отжига расстояние $R_{\mathrm{Pt}-\mathrm{Pt}}$ уменьшается на $0.05 \AA$, а расстояние $R_{\mathrm{Cu}-\mathrm{Cu}}$, напротив, возрастает на $0.09 \AA$. Изменение же расстояния $R_{\mathrm{Pt}-\mathrm{Cu}}$ оказывается равным $0.02 \AA$, что не намного больше погрешности его определения. Похожие изменения наблюдаются и для расстояний, рассчитанных для модельных кластеров (табл. 3): при переходе от архитектуры ядро-оболочка к твердым растворам расстояние $\left\langle R_{\mathrm{Pt}-\mathrm{Pt}}\right\rangle$ немного уменьшается (на $0.03 \AA$ ), расстояние $\left\langle R_{\mathrm{Pt}-\mathrm{Cu}}\right\rangle$ меняется на 0.02-0.03 $\AA$ в зависимости от степени упорядочения раствора. Наиболее существенны изменения расстояния $\left\langle R_{\mathrm{Cu}-\mathrm{Cu}}\right\rangle$ : при переходе к неупорядоченному твердому раствору оно увеличивается на $0.06 \AA$, а к упорядоченному - на $0.1 \AA$, что в большей степени соответствует данным EXAFS. Вероятнее всего, в составе катализаторов после их термической обработки присутствуют наночастицы со структурой как однородного твердого раствора, так и упорядоченного твердого раствора, или интерметаллида, сверхструктурные отражения которого наблюдаются на рентгеновских дифрактограммах.

\section{4. Заключение}

Методом последовательного химического восстановления $\mathrm{Cu}^{2+}$ и $\mathrm{Pt}(\mathrm{IV})$ в углеродной суспензии без промежуточного извлечения материала $\mathrm{Cu} / \mathrm{C}$ получены композитные материалы $\mathrm{PtCu} / \mathrm{C}$, характеризующиеся массовой долей металлического компонента $\sim 30 \%$. Структурные исследования приготовленных, а также подвергнутых температурной обработке при $350^{\circ} \mathrm{C}$ материалов выполнены методами TEM, XRD и EXAFS. Компонентный состав, определенный методом рентгеновской флуоресценции, соответствует атомарному соотношению металлов $\mathrm{Pt}: \mathrm{Cu}=0.8: 1$ в материалах как до, так и после обработки, что в достаточной степени отвечает ожидаемому соотношению компонентов $1: 1$. Согласованный анализ TEM-микрофотографий, XRD-профилей и EXAFS-спектров позволил установить, что в состав полученных материалов входят биметаллические наночастицы $\mathrm{PtCu}$ со структурой ядро-оболочка, а также оксиды одно- и двухвалентной меди. Термическая обработка электрокатализаторов при $350^{\circ} \mathrm{C}$ приводит к разрушению архитектуры ядро-оболочка и сплавлению части биметаллических наночастиц с формированием как однородных, так и упорядоченных твердых раствоpoв $\mathrm{PtCu}$, а также к частичному восстановлению медных оксидов. Метод EXAFS-спектроскопии позволяет надежно идентифицировать различия в однородности распределения атомов меди и платины в наночастицах и тем самым позволяет отличать катализаторы с высоким содержанием наночастиц $\mathrm{PtCu}$ со структурой ядро-оболочка от аналогичных по составу частиц со структурой твердого раствора.

Термообработка при высоких $\left(>300^{\circ} \mathrm{C}\right)$ температурах с последующим анализом изменений положений максимумов в XRD-профилях может быть использована для определения устойчивости архитектуры ядро-оболочка синтезируемых наночастиц $\mathrm{Pt} M$. Полученные результаты показывают, что следующей важной задачей является поиск температур, обработка при которых приводила бы к позитивным эффектам как с точки зрения улучшения качества платиновой оболочки наночастиц (повышение ее сплошности), так и с точки зрения стабилизации каталитических характеристик материалов, получаемых на основе таких наночастиц. Для решения данной задачи планируется проведение структурных исследований и электрохимических испытаний электрокатализаторов $\mathrm{Pt} M / \mathrm{C}(M=\mathrm{Cu}, \mathrm{Ni}, \mathrm{Co})$, полученных методом последовательного восстановления компонентов на углеродном носителе и обработанных при различных температурах в диапазоне от 200 до $350^{\circ} \mathrm{C}$. 


\section{Список литературы}

[1] J.R.C. Salgado, E. Antolini, E.R. Gonzalez. J. Power Sources 141, 13 (2005).

[2] V.V. Pryadchenko, V.V. Srabionyan, E.B. Mikheykina, L.A. Avakyan, V.Y. Murzin, Y.V. Zubavichus, I. Zizak, V.E. Guterman, L.A. Bugaev. J. Phys. Chem. C 119, 3217 (2015).

[3] V.V. Pryadchenko, V.V. Srabionyan, A.A. Kurzin, N.V. Bulat, D.B. Shemet, L.A. Avakyan, S.V. Belenov, V.A. Volochaev, I. Zizak, V.E. Guterman, L.A. Bugaev. Appl. Catal. A 525, 226 (2016).

[4] В.В. Срабионян, В.В. Прядченко, А.А. Курзин, С.В. Беленов, Л.А. Авакян, В.Е. Гутерман, Л.А. Бугаев. ФТТ 58, 730 (2016).

[5] V.E. Guterman, S.V. Belenov, A.Y. Pakharev, M. Min, N.Y. Tabachkova, E.B. Mikheykina, L.L. Vysochina, T.A. Lastovina. Int. J. Hydrogen Energy 41, 1609 (2016).

[6] C.W.B. Bezerra, L. Zhang, H. Liu, K. Lee, A.L.B. Marques, E.P. Marques, H. Wang, J. Zhang. J. Power Sources 173, 891 (2007).

[7] L. Xiong, A. Manthiram. J. Electrochem. Soc. 152, A697 (2005).

[8] D.L. Wang, H.L.L. Xin, R. Hovden, H.S. Wang, Y.C. Yu, D.A. Muller, F.J. DiSalvo, H.D. Abruna. Nat. Mater. 12, 81 (2013).

[9] A.N. Valisi, T. Maiyalagan, L. Khotseng, V. Linkov, S. Pasupathi. Electrocatalysis 3, 108 (2012).

[10] С.В. Беленов, В.А. Волочаев, В.В. Прядченко, В.В. Срабионян, Д.Б. Шемет, Н.Ю. Табачкова, В.Е. Гутерман. Рос. нанотехнологии, в печати (2017).

[11] D.C. Koningsberger, B.L. Mojet, G.E. van Dorssen, D.E. Ramaker. Top. Catal. 10, 143 (2000).

[12] G.B. Sukharina, A.N. Kravtsova, A.V. Soldatov, Y.V. Zubavichus, N.A. Kryuchkova, L.N. Mazalov. J. Phys. Conf. Ser. 190, 12148 (2009).

[13] G.B. Sukharina, A.V. Soldatov, O.N. Batuk, M.A. Denecke. Nucl. Instr. Meth. Phys. Res. A 603, 125 (2009).

[14] C. Lamberti, J.A. van Bokhoven. In: $X$-ray absorption and $X$-ray Emission spectroscopy: theory and applications / Eds J.A. van Bokhoven, C. Lamberti. Wiley (2016). P. 351-383.

[15] С.А. Киракосян, А.А. Алексеенко, В.Е. Гутерман, В.А. Волочаев, Н.Ю. Табачкова. Рос. нанотехнологии 11, 5-6, 23 (2016).

[16] M. Oezaslan, F. Hasché, P. Strasser. J. Electrochem. Soc. 159, B444 (2012).

[17] $X$-ray absorption and $X$-ray emission spectroscopy: theory and applications / Eds J. van Bokhoven, C. Lamberti. Wiley (2016). $896 \mathrm{p}$.

[18] M. Newville. J. Synchrotron Rad. 8, 322 (2001).

[19] B. Ravel, M. Newville. J. Synchrotron Rad. 12, 537 (2005).

[20] V.V. Srabionyan, A.L. Bugaev, V.V. Pryadchenko, L.A. Avakyan, J.A. van Bokhoven, L.A. Bugaev. J. Phys. Chem. Solids 75, 470 (2014).

[21] S. Åsbrink, L.J. Norrby. Acta Cryst. B 26, 8 (1970).

[22] M. Heinz, V.V. Srabionyan, A.L. Bugaev, V.V. Pryadchenko, E.V. Ishenko, L.A. Avakyan, Y.V. Zubavichus, J. Ihlemann, J. Meinertz, E. Pippel, M. Dubiel, L.A. Bugaev. J. Alloys Compd. 681, 307 (2016).
[23] V.V. Srabionyan, A.L. Bugaev, V.V. Pryadchenko, A.V. Makhiboroda, E.B. Rusakova, L.A. Avakyan, R. Schneider, M. Dubiel, L.A. Bugaev. J. Non.-Cryst. Solids 382, 24 (2013).

[24] S.Y. Lee, N. Mettlach, N. Nguyen, Y.M. Sun, J.M. White. Appl. Surf. Sci. 206, 102 (2003).

[25] K.W. Jacobsen, P. Stoltze, J.K. Nørskov. Surf. Sci. 366, 394 (1996).

[26] C.G. Broyden. Math. Comput. 24, 365 (1970).

[27] D. Goldfarb. Math. Comp. 24, 23 (1970).

[28] D.F. Shanno, P.C. Kettler. Math. Comp. 24, 657 (1970).

[29] T. Schlick. Molecular modeling and simulation: an interdisciplinary guide. Springer-Verlag, N.Y. (2010). 723 p.

[30] S.R. Bahn, K.W. Jacobsen. Comput. Sci. Eng. 4, 56 (2002).

[31] C. Kittel, P. McEuen. Introduction to solid state physics. Wiley, N.Y. (1986). 646 p. 